\title{
Seleção de genótipos de amendoim forrageiro para cobertura do solo e produção de biomassa aérea no período de estabelecimento utilizando-se metodologia de modelos mistos ${ }^{1}$
}

\author{
Giselle Mariano Lessa de Assis ${ }^{2}$, Judson Ferreira Valentim², José Marques Carneiro Júnior², \\ José Marlo Araújo de Azevedo ${ }^{3}$, Aliedson Sampaio Ferreira ${ }^{2}$ \\ 1 Projeto financiado parcialmente com recursos do Banco da Amazônia e do FDCT/FUNTAC. \\ 2 Embrapa Acre, BR 364, km 14, CP 321, CEP: 69908-970, Rio Branco, AC. \\ ${ }^{3}$ Universidade Federal do Acre.
}

RESUMO - Objetivou-se estimar parâmetros genéticos e selecionar genótipos de amendoim forrageiro para maior cobertura do solo e produção de biomassa aérea durante o período de estabelecimento nas condições ambientais do Acre. A área experimental foi estabelecida em dezembro de 2005. O experimento foi realizado em delineamento de blocos ao acaso com quatro repetições utilizando-se 21 genótipos de amendoim forrageiro, incluindo três cultivares (Amarillo, Alqueire $1 \mathrm{e}$ Belmonte). A seleção dos genótipos foi realizada considerando a cobertura do solo e a produção de matéria seca. As avaliações de cobertura do solo foram realizadas entre janeiro e outubro de 2006, em intervalos de quatro semanas. A produção de matéria seca foi mensurada 304 dias após o plantio. Os componentes de variância foram estimados pelo Método da Máxima Verossimilhança Restrita (REML) e os valores genotípicos foram preditos pelo método da Melhor Predição Linear Não-Viesada (BLUP), conforme metodologia dos modelos mistos.Verificou-se a presença de variabilidade genética para ambas as características. As herdabilidades individuais foram de magnitude mediana, com valores de 0,36 a 0,58 para as características cobertura do solo e produção de matéria seca, respectivamente. A maior variabilidade entre os genótipos para cobertura do solo ocorreu entre a $12^{\mathrm{a}}$ e a $16^{\mathrm{a}}$ semana após o plantio, indicando que esse intervalo é o mais adequado para a seleção de genótipos de cobertura mais rápida do solo. Os valores genotípicos para produção de matéria seca variaram de 1.609 a $4.132 \mathrm{~kg} / \mathrm{ha}$ para os genótipos BRA 015083 e BRA 040550 , respectivamente. Os genótipos selecionados para maior cobertura do solo e produção de biomassa aérea durante o período de estabelecimento foram Belmonte, Amarillo, BRA 040550, BRA 039187, Alqueire 1, BRA 039799 e BRA 035033.

Palavras-chave: Arachis, BLUP, dados longitudinais, leguminosas forrageiras, parâmetros genéticos, REML

\section{Selection of forage peanut genotypes for ground cover and aerial biomass production during establishment period using mixed model methodology}

ABSTRACT - This study aimed to estimate genetic parameters and to select genotypes of forage peanut with greater ground cover and aerial biomass production during establishment period in the environmental conditions of Acre. The experiment was planted in December/2005, in a randomized block with four repetitions. Twenty one genotypes of forage peanut were evaluated, including three cultivars: Amarillo, Alqueire 1, and Belmonte. Genotype selection was based on ground cover and dry matter production. The ground cover evaluations took place between January and October 2006, at intervals of approximately four weeks. The dry matter production was measured 304 days after planting. The variance components were estimated by Restricted Maximum Likelihood Method (REML) and genotypic values were predicted by Best Linear Unbiased Prediction (BLUP), according the methodology of mixed models. Presence of genetic variability was verified for both traits. Individual heritabilities in the wide sense were of medium magnitude, presenting values of 0.36 to 0.58 for the traits ground cover and dry matter production, respectively. The largest variability among genotypes for ground cover occurred between the $12^{\text {th }}$ and $16^{\text {th }}$ week after planting, indicating that this interval is the most appropriate to select genotypes that cover the ground more quickly. Genotypic values for dry matter production ranged from 1,609 to 4,132 $\mathrm{kg} / \mathrm{ha}$ for genotypes BRA 015083 and BRA 040550, respectively. The genotypes selected for greater ground cover and aerial biomass production during establishment period were Belmonte, Amarillo, BRA 040550, BRA 039187, Alqueire 1, BRA 039799 and BRA 035033.

Key Words: Arachis, BLUP, forage legumes, genetic parameters, longitudinal data, REML

Este artigo foi recebido em 13/7/2007 e aprovado em 12/5/2008.

Correspondências devem ser enviadas paragiselle@cpafac.embrapa.br. 


\section{Introdução}

As pastagens cultivadas brasileiras são pouco diversificadas e constituídas principalmente por espécies de Brachiaria. Os cultivares mais utilizados são apomíticos, o que torna as pastagens ainda mais vulneráveis geneticamente. Um exemplo atual dessa vulnerabilidade é a ocorrência da síndrome da morte do capim-marandu nas regiões Norte e Centro-Oeste do País (Barbosa, 2006).

Além da baixa diversificação, verifica-se a degradação das pastagens, que torna a atividade pouco eficiente, levando o produtor a desmatar áreas de alta biodiversidade, ocupadas por floresta tropical (Ribeiro et al., 2005). Esses problemas podem ser reduzidos com o uso de leguminosas forrageiras em consórcio com gramíneas, que tem como principais vantagens o aumento do valor nutritivo das pastagens e a fixação biológica de nitrogênio. O cultivo de leguminosas em pastagens no Brasil, no entanto, ainda é pouco comum, principalmente pelo fato de as leguminosas não serem persistentes no sistema, cujo manejo é usualmente voltado para atender às necessidades fisiológicas das gramíneas tropicais (grupo fotossintético C4), diferentes das leguminosas forrageiras (grupo fotossintético C3). Entre as causas do manejo inadequado das pastagens, destacam-se o uso de espécies de gramíneas e leguminosas incompatíveis, a utilização de misturas com grande quantidade de sementes da gramínea e pouca da leguminosa, o uso de queimadas para eliminar a forragem não consumida, o superpastejo durante o período de crescimento e a aplicação de herbicidas no controle de invasoras (Roberts, 1974; Roberts, 1982). Além desses fatores, o estabelecimento de cultivares não adaptados às condições brasileiras teve impacto negativo nas experiências com pastagens consorciadas (Pereira, 2001).

Entre as leguminosas forrageiras tropicais, o amendoim forrageiro (Arachis pintoi Kaprovickas \& Gregory) se destaca por manter associações estáveis com gramíneas agressivas sob pastejo intensivo por mais de dez anos (Kerridge, 1995), em virtude de suas características peculiares, que lhe conferem vantagens nos sistemas de consórcio (Pereira, 2001): permanência na pastagem mesmo sob condições de manejo adversas; resistência ao pastejo, pois seus estolões enraízam fortemente; pontos de crescimento meristemático bem protegidos; e boa reserva de sementes enterradas. No entanto, alguns autores ressaltam como desvantagem o lento estabelecimento do amendoim forrageiro (A. pintoi) (Argel \& Pizarro, 1992; Pizarro \& Carvalho, 1996). Estes resultados devem ser analisados com cautela, pois estes trabalhos se baseiam em poucos genótipos, sendo que, atualmente, existem coletados mais de 200 acessos da secção Caulorrizhae (Peñaloza et al., 2005), entre os quais poucos foram avaliados quanto à velocidade de estabelecimento (Pizarro et al., 1993; Valentim et al., 2003). Os resultados dessas avaliações comprovam que existe variabilidade para a característica cobertura do solo. No trópico úmido, as altas temperaturas agem sobre o solo descoberto, acelerando a decomposição da matéria orgânica, e o vento e as chuvas favorecem a erosão e a compactação do solo. A rápida e eficiente cobertura do solo pelas plantas forrageiras é essencial para garantir a conservação dos nutrientes do solo e, consequientemente, a longevidade da pastagem. Além disso, o lento estabelecimento facilita a ocupação do solo por plantas daninhas (Dias Filho, 2005) e retarda a entrada dos animais na pastagem.

Esse trabalho foi realizado com o objetivo de estimar parâmetros genéticos e selecionar genótipos de amendoim forrageiro para maior cobertura do solo e produção de biomassa aérea durante o período de estabelecimento, por meio da utilização de mudas, nas condições ambientais do Acre, adotando metodologia de modelos mistos.

\section{Material e Métodos}

O experimento foi estabelecido no Campo Experimental da Embrapa Acre, em dezembro de 2005, em argissolo vermelho amarelo com textura média. $\mathrm{O}$ delineamento experimental utilizado foi o de blocos ao acaso com quatro repetições. Foram avaliados 21 genótipos de amendoim forrageiro: 11 acessos de Arachis pintoi Kaprovickas \& Gregory; 4 de A. repens Handro; 2 híbridos intraespecíficos de $A$. pintoi (F1s), 1 híbrido interespecífico de $A$. pintoi $\times$ A. repens $(\mathrm{F} 1)$ e 3 cultivares de $A$. pintoi (Tabela 1$)$.

Os genótipos foram plantados em parcelas de $6 \mathrm{~m}^{2}$ $(2 \mathrm{~m} \times 3 \mathrm{~m})$, totalizando área útil de $2 \mathrm{~m}^{2}$. O plantio foi realizado com material vegetativo, em covas de $10 \mathrm{~cm}$ de profundidade, com espaçamento de 0,50 m entre covas e entre linhas. Os seguintes critérios foram utilizados para padronização das mudas: os estolões possuíam 20 a $30 \mathrm{~cm}$ de comprimento; em cada cova foram colocados dois estolões, cada um com cinco nós, de modo que três ficaram cobertos pelo solo. As mudas de todos os genótipos foram produzidas em viveiro, no próprio Campo Experimental, nas mesmas condições ambientais. A área experimental foi adubada conforme resultados da análise de solo, com calcário dolomítico (500 kg/ha) e aplicação de $\mathrm{P}_{2} \mathrm{O}_{5}(50 \mathrm{~kg} / \mathrm{ha}), \mathrm{K}_{2} \mathrm{O}(30 \mathrm{~kg} / \mathrm{ha})$ e FTE - micronutrientes (40 kg/ha) em cobertura. Foram realizadas capinas manuais durante o período experimental para controle das invasoras entre e dentro das parcelas.

As características avaliadas foram cobertura do solo (\%) e produção de matéria seca (kg/ha). A cobertura do solo 
foi avaliada em intervalos de aproximadamente quatro semanas, obtendo-se dez medições ao longo do período experimental. Em outubro de 2006, realizou-se o primeiro corte para quantificação da matéria seca acumulada no período de estabelecimento e análise da produção de matéria seca (kg/ha). A determinação da matéria seca foi realizada na área útil da parcela, cortando-se a biomassa aérea a $1 \mathrm{~cm}$ de altura do solo. As amostras foram secas em estufa de ventilação forçada a $55^{\circ} \mathrm{C}$, por 72 horas.

O seguinte modelo estatístico foi utilizado para cobertura do solo:

$$
y_{i j k}=\mu+g_{i}+b_{j}+m_{k}+g b_{i j}+g m_{i k}+b m_{j k}+e_{i j k},
$$

em que $\mu=$ média geral; $g_{i}=$ efeito do genótipo $i ; b_{j}=$ efeito do bloco $j ; m_{k}=$ efeito da medição $k ; g b_{i j}=$ efeito da interação genótipos $\times$ blocos; $g m_{i k}=$ efeito da interação genótipos $\times$ medições; $b m_{j k}=$ efeito da interação blocos $\times$ medições; e $e_{i j k}=$ efeito residual. Para produção de matéria seca, o modelo utilizado não incluiu o efeito de medição e suas interações.

Os parâmetros genéticos foram estimados pelo método de máxima verossimilhança restrita (REML) e os valores genotípicos foram preditos pelo método da melhor predição linear não-viesada (BLUP), conforme metodologia de modelos mistos (Henderson, 1984). Essa metodologia, inicialmente utilizada na avaliação genética animal, tem despertado o interesse de melhoristas vegetais, principalmente no melhoramento de culturas perenes. Entre outras características, permite a avaliação de elevado número de genótipos, pode ser aplicada a dados desbalanceados,

Tabela 1 - Genótipos de amendoim forrageiro avaliados durante o estabelecimento no período de dezembro de 2005 a outubro de 2006

\begin{tabular}{cc}
\hline BRA & Espécie \\
\hline 014931 & A. pintoi \\
033260 & A. repens \\
039799 & A. pintoi \\
035068 & A. pintoi x A. repens \\
035041 & A. pintoi $\mathrm{x}$ A. pintoi \\
035033 & A. pintoi $\mathrm{x}$ A. pintoi \\
040894 & A. pintoi \\
030333 & A. pintoi \\
039187 & A. pintoi \\
014991 & A. pintoi \\
015083 & A. pintoi \\
035114 & A. pintoi \\
032352 & A. repens \\
034436 & A. repens \\
032379 & A. repens \\
032409 & A. pintoi \\
034142 & A. pintoi \\
040550 & A. pintoi \\
037036 & A. pintoi cv. Alqueire 1 \\
031828 & pintoi cv. Belmonte \\
013251 & Amarillo \\
\hline
\end{tabular}

considera as diversas medições no mesmo indivíduo ao longo do tempo, além de ser um método ótimo, que minimiza o erro quadrático médio.

A acurácia seletiva foi estimada para ambas as características. A significância dos componentes de variância foi testada pelo Teste da Razão de Verossimilhança. Os valores genotípicos para cobertura do solo foram preditos para cada uma das medições, considerando, no entanto, a informação contida em todo o conjunto de dados. Os genótipos foram classificados conforme seu valor genotípico predito, tanto para cobertura do solo quanto para produção de matéria seca.

A identificação dos genótipos superiores, considerando as duas características simultaneamente, foi realizada com base no índice proposto por Elston (1963) modificado, pois, em vez de se utilizar a média fenotípica, empregou-se o valor genotípico predito. Assim: $I=\omega_{1} \omega_{2}$, de modo que $\omega_{j}=x_{j}-k_{j}$, em que $x_{j}=$ valor genotípico predito do indivíduo $j ; k_{j}=$ valor mínimo estabelecido. $\mathrm{O}$ valor mínimo estabelecido foi a média dos valores genotípicos, em que é considerado nulo nos casos em que ficou abaixo do nível mínimo preestabelecido.

As análises foram realizadas por meio do programa SELEGEN (Resende, 2002).

\section{Resultados e Discussão}

A variabilidade genotípica foi significativa para a produção de matéria seca (PMS) e para a cobertura do solo (CS), o que viabiliza a seleção de genótipos superiores (Tabela 2). As herdabilidades foram de magnitude mediana, o que comprova a importância de se realizar a seleção dos genótipos com base nos seus valores genotípicos e não nas médias observadas. Ressalta-se que a herdabilidade estimada foi a de sentido amplo, que envolve a variância genética aditiva e a de dominância, importante no melhoramento de plantas de propagação vegetativa, uma vez que, nesse caso, o genótipo é totalmente herdado. A acurácia seletiva, que corresponde à correlação entre o valor

Tabela 2 - Média geral, variância genotípica $\left(\mathrm{V}_{\mathrm{g}}\right)$, herdabilidade individual no sentido amplo $\left(\mathrm{h}^{2}\right)$ e acurácia $\left(\hat{r}_{\hat{g} g}\right)$ estimadas para cobertura do solo e produção de matéria seca de genótipos de amendoim forrageiro

\begin{tabular}{lcccc}
\hline Característica & Média & $\mathrm{V}_{\mathrm{g}}$ & $\mathrm{h}^{2}$ & $\hat{r}_{\hat{g} g}$ \\
\hline $\begin{array}{l}\text { Cobertura do } \\
\text { solo (\%) }\end{array}$ & 58,13 & $157,65 * *$ & $0,36 * *$ & 0,92 \\
$\begin{array}{l}\text { Produção de } \\
\text { MS (kg/ha) }\end{array}$ & $3.131,94$ & $687.384,42 * *$ & $0,58 * *$ & 0,92 \\
\hline
\end{tabular}

** Significativo a 1\% de probabilidade pelo Teste da Razão de VerossimiIhança da deviance (teste de qui-quadrado, com um grau de liberdade). 
fenotípico (critério de seleção) e o valor genético verdadeiro, foi classificada como muito alta $(>0,90)$ para ambas as características.

A correlação entre os valores genotípicos preditos para cobertura do solo e produção de matéria seca foi igual a 0,85 ( $\mathrm{P}<0,0001)$ e indica que genótipos com maior cobertura do solo também acumulam maior quantidade de matéria seca (Assis et al., 2007).

A metodologia empregada neste estudo permite predizer os valores genotípicos para cada uma das medições realizadas, considerando, no entanto, a informação contida em todo o conjunto de dados (Henderson, 1984). A variabilidade dos valores genotípicos varia conforme o mês de avaliação (Figura 1). Em janeiro de 2006, praticamente não se observou variação entre os valores genotípicos (desvio- padrão igual a 1\%), portanto, não foi possível diferenciar os genótipos quanto à cobertura do solo quatro semanas após o plantio. A maior variabilidade entre os genótipos foi detectada entre a $12^{\mathrm{a}}$ e $16^{\mathrm{a}}$ semana após o plantio (março e abril), com desvios-padrão de 16 e 15\%, respectivamente. A partir do mês de junho, pouca variabilidade foi observada, principalmente quando desconsiderado o acesso BRA 014931, cuja cobertura do solo diminuiu com a ocorrência de rizoctoniose. Nesse período, apesar da baixa magnitude, a maior variabilidade ocorreu no mês de agosto e possibilitou identificar em quais genótipos foi menor a senescência das folhas atribuída ao déficit hídrico (BRA 039187, BRA 035033 e Amarillo). Ressalta-se que, na região onde foi realizado o experimento, a estação chuvosa se estende de outubro a abril (maio é a estação de transição entre a estação chuvosa e a seca) e a estação seca se estende de junho a agosto (setembro é o mês de transição entre a seca e a estação chuvosa). Na estação chuvosa, ocorre $80 \%$ da precipitação anual.

Neste estudo, optou-se pela seleção baseada nos valores genotípicos preditos considerando os dados das quatro primeiras medições (Figura 1). A correlação entre os valores genotípicos para cobertura do solo, considerando as dez medições e, para cobertura do solo, considerando as quatro primeiras medições (16 semanas após o plantio), foi igual a $0,80(\mathrm{P}<0,0001)$. Esse valor confirma o alto grau de associação linear entre os valores genotípicos das épocas.

Os genótipos Belmonte, BRA 014931, BRA 039187, Amarillo, BRA 040550, Alqueire 1, BRA 035033, BRA 039799 e BRA 035114 se destacaram em cobertura do solo (Tabela 3), com valores genotípicos preditos superiores à média geral $\left(22,91 \%\right.$ até a $16^{\mathrm{a}}$ semana após o plantio). O acesso BRA 035033 é um híbrido F1 e, no caso de utilização imediata, sua propagação deve ser realizada por via vegetativa. A utilização de híbridos cuja forma de propagação seja por sementes exige estratégia diferenciada, em que, após a hibridação, sucessivas gerações de autofecundação sejam avançadas. A classificação dos quatro acessos de A. repens foi desfavorável, comprovando que, nas condições desta avaliação, esses acessos apresentaram lento estabelecimento. O híbrido interespecífico BRA 035068 apresentou classificação intermediária $\left(12^{\circ}\right)$ e foi superior aos acessos de $A$. repens; todavia, na classificação geral,

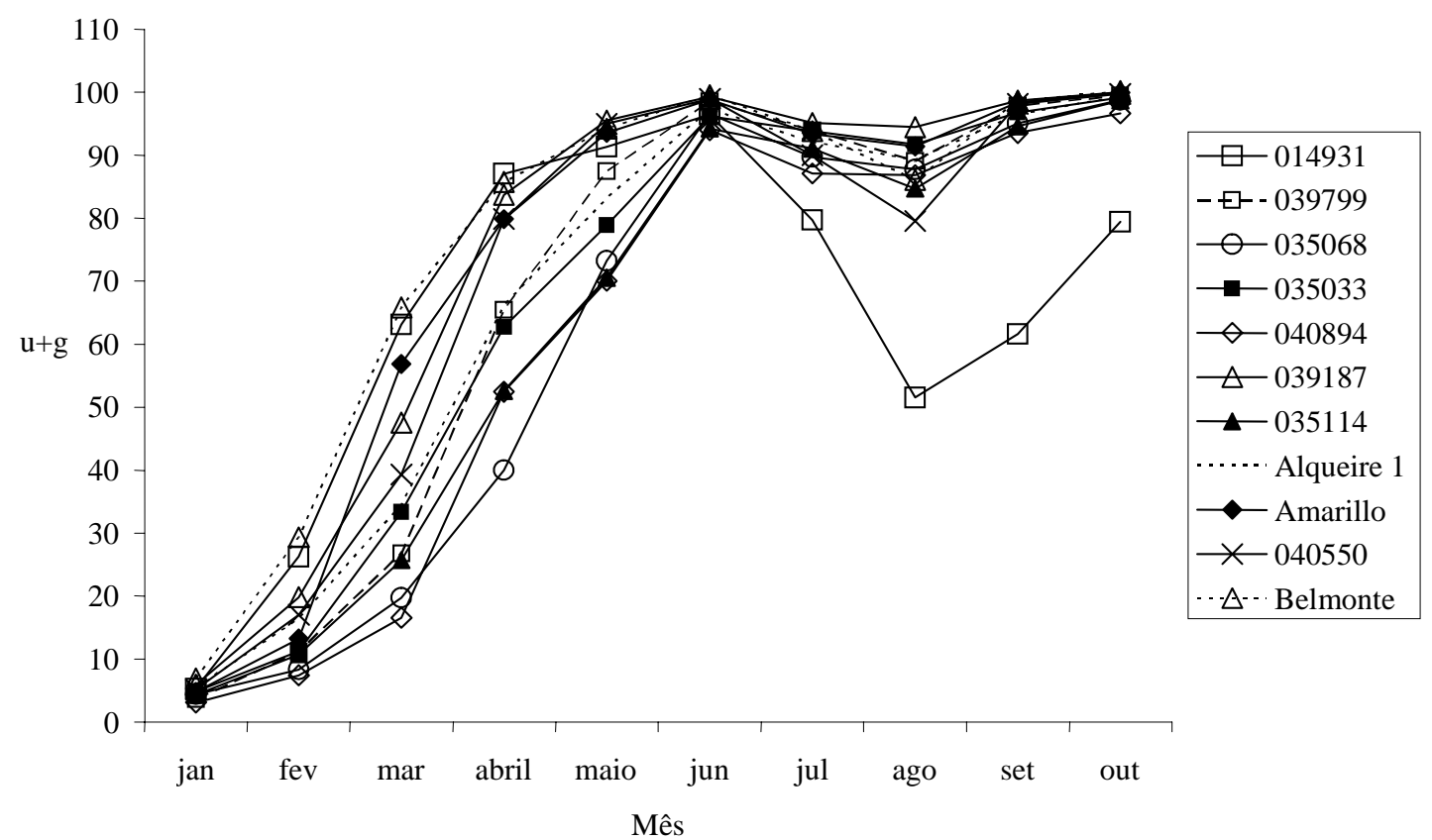

Figura 1 - Melhor preditor linear não-viesado (BLUP) dos valores genotípicos somado à média geral $(u+g)$ dos genótipos superiores de amendoim forrageiro para a característica cobertura do solo em cada medição. 
esse híbrido ainda se manteve abaixo da média para cobertura do solo.

Argel \& Pizarro (1992) descreveram resultados que comprovam as diferenças na cobertura do solo do mesmo genótipo (cv. Amarillo - BRA 013251), plantado em diversas condições edafoclimáticas na Colômbia. A cobertura do solo foi avaliada 12 semanas após o plantio e variou de $1 \%$ a $35 \%$ em regiões cuja precipitação total neste período foi de 487 e $787 \mathrm{~mm}$, respectivamente.

Esses resultados são bem inferiores aos obtidos em Rio Branco, Acre, onde o cultivar Amarillo (BRA 013251) apresentou $61,25 \%$ de cobertura do solo 12 semanas após o plantio. Nesse mesmo período, o genótipo que mais se destacou foi o cultivar Belmonte (BRA 031828), com média fenotípica de cobertura do solo de $71,75 \%$. O pior desempenho foi do genótipo BRA 015083, cuja cobertura do solo 12 semanas após o plantio foi de $8 \%$.

Argel (1995), no entanto, relatou que o cultivar Amarillo (BRA 013251) atingiu 100\% de cobertura do solo em apenas oito semanas após o plantio, no Panamá, e que resultados similares também foram obtidos na Costa Rica. Apesar da variabilidade genética para cobertura do solo e produção de matéria seca, que torna viável selecionar genótipos superiores para velocidade de estabelecimento, outros fatores

Tabela 3 - Melhor preditor linear não-viesado (BLUP) dos genótipos de amendoim forrageiro avaliados quanto à cobertura do solo (CS) até a $16^{\mathrm{a}}$ semana após o plantio e quanto à produção de matéria seca (PMS) 304 dias após o plantio

\begin{tabular}{|c|c|c|}
\hline \multirow[t]{2}{*}{ Genótipo (BRA) } & \multicolumn{2}{|c|}{ BLUP $(\mathrm{u}+\mathrm{g})$} \\
\hline & CS $(\%)$ & PMS (kg/ha) \\
\hline Belmonte & $43,08\left(1^{\circ}\right)$ & $3.815\left(4^{\circ}\right)$ \\
\hline 014931 & $42,61\left(2^{\circ}\right)$ & $2.240\left(18^{\circ}\right)$ \\
\hline 039187 & $36,31\left(3^{\circ}\right)$ & $3.688\left(7^{\circ}\right)$ \\
\hline Amarillo & $35,89\left(4^{\circ}\right)$ & $4.096\left(2^{\circ}\right)$ \\
\hline 040550 & $33,10\left(5^{\circ}\right)$ & $4.133\left(1^{\circ}\right)$ \\
\hline Alqueire 1 & $29,04\left(6^{\circ}\right)$ & $3.777 \quad\left(5^{\circ}\right)$ \\
\hline 035033 & $26,85\left(7^{\circ}\right)$ & $3.573\left(8^{\circ}\right)$ \\
\hline 039799 & $25,64\left(8^{\circ}\right)$ & $3.904\left(3^{\circ}\right)$ \\
\hline 035114 & $22,93\left(9^{\circ}\right)$ & $3.272\left(11^{\circ}\right)$ \\
\hline 030333 & $22,18\left(10^{\circ}\right)$ & $3.099\left(12^{\circ}\right)$ \\
\hline 040894 & $19,99\left(11^{\circ}\right)$ & $3.418\left(10^{\circ}\right)$ \\
\hline 035068 & $18,36\left(12^{\circ}\right)$ & $3.755\left(6^{\circ}\right)$ \\
\hline 034142 & $18,27\left(13^{\circ}\right)$ & $1.618\left(20^{\circ}\right)$ \\
\hline 035041 & $17,24\left(14^{\circ}\right)$ & $1.964\left(19^{\circ}\right)$ \\
\hline 014991 & $16,17\left(15^{\circ}\right)$ & $3.442\left(9^{\circ}\right)$ \\
\hline 033260 & $14,63\left(16^{\circ}\right)$ & $2.689\left(17^{\circ}\right)$ \\
\hline 032409 & $13,37\left(17^{\circ}\right)$ & $2.912\left(15^{\circ}\right)$ \\
\hline 032379 & $12,02\left(18^{\circ}\right)$ & $2.864\left(16^{\circ}\right)$ \\
\hline 032352 & $11,65\left(19^{\circ}\right)$ & $2.959\left(13^{\circ}\right)$ \\
\hline 015083 & $10,95\left(20^{\circ}\right)$ & $1.609\left(21^{\circ}\right)$ \\
\hline 034436 & $10,85\left(21^{\circ}\right)$ & $2.946\left(14^{\circ}\right)$ \\
\hline
\end{tabular}

O valor entre parênteses refere-se à classificação do genótipo para cada característica.
(Argel, 1995; Cruz et al., 1995) parecem influenciar significativamente o estabelecimento do amendoim forrageiro, como: disponibilidade de umidade no solo, tipo de solo e taxa de semeadura ou densidade de plantio e tipo de propágulo. Ressalta-se que o plantio foi realizado com material vegetativo (estolões) e que resultados de pesquisas comprovam que o estabelecimento do amendoim forrageiro é mais rápido quando o plantio é feito por sementes (Balzon, 2005; Fisher \& Cruz, 1995).

Em outro experimento conduzido em Rio Branco, Acre, Valentim et al. (2003) verificaram que, dez semanas após o plantio, as médias observadas para os cultivares Belmonte e Amarillo foram de 96 e $86 \%$ de cobertura do solo, respectivamente. Esse alto desempenho de alguns genótipos está associado à alta disponibilidade de umidade no solo e à alta densidade de plantio utilizada no experimento (espaçamento de 0,50 m entre linhas e de 0,25 m entre plantas). Tem-se verificado que a distância entre as plantas dentro da linha influencia a cobertura do solo e a produção de matéria seca, enquanto o espaçamento entre linhas não tem efeito ou possui efeito menos expressivo sobre estas características (Perin et al., 2003; Machado et al., 2005). Perin et al. (2003) utilizaram os espaçamentos entre sulcos de 0,25 e $0,50 \mathrm{~m}$ e Machado et al. (2005), distâncias entre linhas de 0,25; 0,50; 0,75 e $1,00 \mathrm{~m}$.

Os seguintes genótipos se destacaram quanto à produção de matéria seca acumulada no período de 304 dias após o plantio: BRA 040550, Amarillo, BRA 039799, Belmonte, Alqueire 1, BRA 035068, BRA 039187, BRA, 035033, BRA 014991, BRA 040894 e BRA 035114 (Tabela 3). O acesso BRA 014931 não foi selecionado para esta característica, como esperado, em virtude da severa incidência de rizoctoniose. Por outro lado, o acesso BRA 014991, que não foi selecionado para cobertura do solo, apresentou superioridade genética para produção de matéria seca.

Alguns acessos apresentaram classificações contrastantes para cobertura do solo e produção de matéria seca (valores entre parênteses), embora a correlação de Pearson entre ambas as características tenha sido de alta magnitude. Exemplos: o acesso BRA 014931, o $2^{\circ}$ melhor para cobertura do solo e o $18^{\circ}$ para PMS, foi severamente afetado pela ocorrência de rizoctoniose durante o período de estabelecimento; o híbrido interespecífico BRA 035068, que ficou em $12^{\circ}$ lugar para cobertura do solo e $6^{\circ}$ para PMS; e o acesso BRA 014991, que, apesar da $15^{\text {a }}$ colocação em relação à cobertura do solo, ficou em $9^{\circ}$ lugar para produção de matéria seca.

Segundo Valentim et al. (2003), avaliações conduzidas também em Rio Branco, Acre, identificaram o genótipo 
BRA 040550 como o mais produtivo no período de estabelecimento (120 dias após o plantio). A média da produção de matéria seca deste genótipo foi de $3.011 \mathrm{~kg} / \mathrm{ha}$, enquanto o acesso com pior desempenho (BRA 30872) produziu $786 \mathrm{~kg} / \mathrm{ha}$. Os cultivares Amarillo e Belmonte também se destacaram, com produções de $2.373 \mathrm{~kg} / \mathrm{ha} \mathrm{e}$ $2.693 \mathrm{~kg} / \mathrm{ha}$, respectivamente. Neste estudo, as produções de matéria seca dos genótipos BRA 040550, Amarillo, BRA 039799 e Belmonte foram de 4.312, 4.269, 4.043 e $3.937 \mathrm{~kg} / \mathrm{ha}$, respectivamente, 304 dias após o plantio. Os híbridos BRA 035033 e BRA 035068 produziram, respectivamente, 3.652 e $3.867 \mathrm{~kg} / \mathrm{ha}$, enquanto os acessos de A. repens foram pouco produtivos, com valores fenotípicos abaixo de $3.000 \mathrm{~kg} / \mathrm{ha}$.

Estudos conduzidos na Colômbia comprovaram a existência de acessos de desempenho superior ao do cultivar Maní Forrajero Perenne (BRA 013251), que corresponde ao cultivar Amarillo (Paganella \& Valls, 2002). Nesses estudos, foram avaliados 61 acessos de amendoim forrageiro consorciados com Brachiaria humidicola, em Caldas (Cardenás et al., 1999) e Caquetá (Peters et al., 2000), considerando informações desde o estabelecimento até um período de dois anos sob pastejo. Os autores identificaram acessos superiores para uso como forrageira, cobertura e adubo verde em Caquetá (17 acessos) e em Caldas (13 acessos). Entre esses acessos superiores, somente o CIAT 18747 (que corresponde ao BRA 015083) foi avaliado neste estudo. No entanto, o desempenho do acesso BRA 015083 foi desfavorável nas condições edafoclimáticas de Rio Branco (Figura 1; Tabela 3); esse acesso foi o pior em produção de matéria seca e o segundo pior em cobertura do solo, o que ressalta a importância de avaliar os genótipos em várias localidades, em virtude da grande possibilidade de interação genótipo $\times$ ambiente.

Como na seleção dos genótipos devem ser consideradas as duas características simultaneamente, foi estabelecido um índice de seleção (Elston, 1963), que gera uma variável adicional, resultante da ponderação dos dois caracteres de interesse (Tabela 4).

Os três cultivares avaliados se destacaram nas condições edafoclimáticas do Acre e nenhum dos quatro acessos de $A$. repens foi selecionado para velocidade de estabelecimento. O genótipo BRA 035033, um híbrido intraespecífico de $A$. pintoi, mostrou-se promissor para as características avaliadas, mas, se fosse utilizado na geração em que se encontra, sua propagação deveria ser feita por via vegetativa para evitar possíveis perdas ocasionadas pela segregação decorrente da multiplicação por meio de sementes. Os acessos BRA 039187 e BRA 039799 apresen-
Tabela 4 - Genótipos de amendoim forrageiro selecionados em Rio Branco, Acre, utilizando-se o índice de seleção, com adaptações, descrito por Elston (1963)

\begin{tabular}{lc}
\hline Genótipo & Índice de seleção \\
\hline Belmonte & 1,38 \\
Amarillo & 1,26 \\
BRA 040550 & 1,02 \\
BRA 039187 & 0,75 \\
Alqueire 1 & 0,40 \\
BRA 039799 & 0,21 \\
BRA 035033 & 0,17 \\
\hline
\end{tabular}

taram também elevado vigor (Assis et al., 2007)e, conforme análise de diversidade genética baseada em caracteres morfológicos (Balzon et al., 2006), o acesso BRA 039799 pertence ao mesmo grupo do cultivar Belmonte. Assim como o cultivar Belmonte, estes acessos parecem produzir poucas sementes, conforme relatado em estudo de caracterização e de distribuição das sementes no solo (Azevedo et al., 2007). A utilização do acesso BRA 014931 em programas de melhoramento deve ser realizada com cautela, pois, apesar de seu rápido estabelecimento e elevado vigor, mostrou-se susceptível no primeiro ano de avaliação à rizoctoniose, que causou redução drástica da cobertura do solo a partir da $28^{\mathrm{a}}$ semana.

\section{Conclusões}

Existe variabilidade genética para as características relacionadas à cobertura do solo $(\%)$ e à produção de biomassa aérea $(\mathrm{kg} / \mathrm{ha})$ no período de estabelecimento de amendoim forrageiro, o que viabiliza a seleção de genótipos superiores. A seleção de genótipos para cobertura do solo deve ser realizada entre a $12^{\mathrm{a}}$ e a $16^{\mathrm{a}}$ semana após o plantio, período de maior variabilidade genotípica. Os genótipos selecionados com base no índice de seleção, considerando simultaneamente as características cobertura do solo e produção de matéria seca, são Belmonte, Amarillo, BRA 040550, BRA 039187, Alqueire 1, BRA 039799 e BRA 035033.

\section{Agradecimento}

À Embrapa Recursos Genéticos e Biotecnologia, representada pelo pesquisador José Francisco Montenegro Valls, pela disponilização dos genótipos de amendoim forrageiro utilizados neste estudo. Ao pesquisador Rivadalve Coelho Gonçalves, pela identificação das doenças observadas nos acessos durante o experimento. 


\section{Literatura Citada}

ARGEL, P.J.; PIZARRO, E.A. Germplasm case study: Arachis pintoi. In: _-_ Pasture for the tropical lowlands: IAT's contribution. Cali: CIAT, 1992, p.57-73.

ASSIS, G.M.L.; VALENTIM, J.F.; CARNEIRO JR., J.M. et al. Correlações genotípicas para características de estabelecimento em amendoim forrageiro. In: REUNIÃO ANUAL DA SOCIEDADE BRASILEIRA DE ZOOTECNIA, 44., 2007, Jaboticabal. Anais... Jaboticabal: Sociedade Brasileira de Zootecnia, 2007. (CD-ROM).

AZEVEDO, J.M.A.; ASSIS, G.M.L.; VALENTIM, J.F. et al. Caracterização morfológica e distribuição de sementes de acessos de amendoim forrageiro no perfil do solo. In: REUNIÃO ANUAL DA SOCIEDADE BRASILEIRA DE ZOOTECNIA, 44., 2007, Jaboticabal. Anais... Jaboticabal: Sociedade Brasileira de Zootecnia, 2007. (CD-ROM).

BALZON, T.A.; ASSIS, G.M.L.; VALENTIM, J.F. et al. Divergência genética de acessos e híbridos de Arachis baseada em caracteres morfológicos. In: REUNIÃO ANUAL DA SOCIEDADE BRASILEIRA DE ZOOTECNIA, 43., 2006, João Pessoa. Anais... João Pessoa: Sociedade Brasileira de Zootecnia, 2006. (CD-ROM).

BALZON, T.A.; VALENTIM, J.F.; ANDRADE, C.M.S. et al. Efeito do material propagativo e de métodos de plantio na produção de biomassa e de sementes do Arachis pintoi Ap 65. In: REUNIÃO ANUAL DA SOCIEDADE BRASILEIRA DE ZOOTECNIA, 42., 2005, Goiânia. Anais... Goiânia: Sociedade Brasileira de Zootecnia, 2005. (CD-ROM).

BARBOSA, R.A. Mortalidade de plantas forrageiras em pastagens nas regiões Centro-Oeste e Norte do Brasil - Introdução ao problema. In: BARBOSA, R.A. (Ed.) Morte de pastos de braquiárias. Campo Grande: Embrapa Gado de Corte, 2006, p.15-22.

CÁRDENAS, E.A.; MAASS, B.L.; PETERS, M. et al. Evaluación de germoplasma nuevo de Arachis pintoi en Colombia. 2. Bosque muy húmedo - premontano (zona cafetera), Caldas. Pasturas Tropicales, v.21, n.2, p.42-59, 1999.

DIAS FILHO, M.B. Degradação de pastagens: processos, causas e estratégias de recuperação. 2.ed. Belém: Embrapa Amazônia Oriental, 2005. 173p.

ELSTON, R.C. A weight-free index for the purpose of ranking or selection with respect to several traits at a time. Biometrics, v.19, p.85-97, 1963.

FISHER, M.J.; CRUZ, P. Algunos aspectos de la ecofisiología de Arachis pintoi. In: KERRIDGE, P.C. (Ed.). Biologia y agronomia de especies forrajeras de Arachis. Cali: Centro Internacional de Agricultura Tropical, 1995. p.56-75.

HENDERSON, C.R. Applications of linear models in animal breeding. Guelph: University Guelph Press, 1984. 423p.

KERRIDGE, P.C. Perspectivas futuras para el uso y estudio de especies forrajeras de Arachis. In: KERRIDGE, P.C. (Ed.). Biologia y agronomia de especies forrajeras de Arachis. Cali: Centro Internacional de Agricultura Tropical, 1995. p.215-223.
MACHADO, A.N.; SIEWERDT, L.; ZONTA. E.P. et al. Rendimento do amendoim forrageiro estabelecido sob diferentes arranjos populacionais de plantas em planossolo. Ciência Animal Brasileira, v.6, n.3, p.151-162, 2005.

PAGANELLA, M.B.; VALLS, J.F.M. Caracterização morfológica de cultivares e acessos selecionados de Arachis pintoi Krapov. \& Gregory. Pasturas Tropicales, v.24, n.2, p.23-30, 2002.

PEÑALOZA, A.P.S.; VALLS, J.F.M.; SILVA, G.P. Coleta de germoplasma de espécies silvestres de amendoim (Arachis L. Leguminosae). In: WALTER, B.M.T.; CAVALCANTI, T.B. (Eds.) Fundamentos para coleta de germoplasma. Brasília: Embrapa Recursos Genéticos e Biotecnologia, 2005. p.307-325.

PEREIRA, J.M. Produção e persistência de leguminosas em pastagens tropicais. In: SIMPÓSIO DE FORRAGICULTURA E PASTAGENS, 2., 2001, Lavras. Anais...Lavras: 2001. p.111-142.

PERIN, A.; GUERRA, J.G.M.; TEIXEIRA, M.G. Cobertura do solo e acumulação de nutrientes pelo amendoim forrageiro. Pesquisa Agropecuária Brasileira, v.38, n.7, p.791-796, 2003.

PETERS, M.; MAASS, B.L.; FRANCO, L.H. et al. Evaluación de germoplasma nuevo de Arachis pintoi en Colombia. 3. Bosque muy húmedo tropical-Piedemonte amazónico, Caquetá. Pasturas Tropicales, v.22, n.2, p.2-28, 2000.

PIZARRO, E.A.; CARVALHO, M.A. Alternative forages for the tropics: Arachis and Paspalum. In: SYMPOSIUM OF THE CROP SCIENCE SOCIETY OF AMERICA, 1996, Seatle. Proceedings... Seatle: 1996. p.1-14.

PIZARRO, E.A.; VALLS, J.F.M.; CARVALHO, M.A. et al. Arachis spp.: introduction and evaluation of new accessions in seasonally flooded land in Brazilian Cerrado. In: INTERNATIONAL GRASSLAND CONGRESS, 17., 1993, Palmerston North. Proceedings... Palmerston North: 1993, p.2146-2148.

RESENDE, M.D.V. O software SELEGEN-REML/BLUP: Sistema Estatístico e Seleção Genética Computadorizada. Colombo: Embrapa Florestas, 2002. (CR-ROM).

RIBEIRO, C.F.A.; ALMEIDA, O.T.; RIBEIRO, S.C.A. et al. Expansão da pecuária de bovinos e desafios de sustentabilidade da atividade na Amazônia legal. In: WORKSHOP BRASIL-JAPÃO EM ENERGIA, MEIOAMBIENTE E DESENVOLVIMENTO SUSTENTÁVEL, 3., 2005, Campinas. Anais eletrônicos... Campinas: UNICAMP, 2005, Disponível em: <http://www.cori.rei.unicamp.br/Brasil Japao3/progjb3.php> Acesso em: 15/5/2006.

ROBERTS, C.R. Some problems of establishment and management of legume-based tropical pastures. Tropical Grasslands, v.8, p.61-67, 1974.

ROBERTS, C.R. Algumas causas comuns dos fracassos das pastagens tropicais de leguminosas e gramíneas em fazendas comerciais e as possíveis soluções. In: TERGAS, L.E.; SANCHEZ, P.A.; SERRÃO, E.A.S. (Eds.) Produção de pastagens em solos ácidos dos trópicos. Brasília: CIAT/Embrapa, 1982. p.433452.

VALENTIM, J.F.; ANDRADE, C.M.S.; MENDONÇA, H.A. et al. Velocidade de estabelecimento de acessos de amendoim forrageiro na Amazônia Ocidental. Revista Brasileira de Zootecnia, v.32, n.6, p.1569-1577, 2003. 